\title{
Interactive Marketing and Application Model in Mobile Electronic Commerce
}

\author{
Jianbo Zhao \\ Xi'an International University, Shaanxi Xi'an, 710077, China
}

Keywords: internet, M-commerce, interactive marketing, application mode, analysis.

\begin{abstract}
Mobile internet that based on the network architecture has entered numerous households, providing a new path for Mobile Electronic Commerce (M-commerce) development. Meanwhile the mobile electronic commerce was carried to users through mobile networks. By exploring the background and history of M-commerce, this paper has focused on the interactive marketing of Mcommerce, to definite the specific characters and applied category from the perspective of scientific program, making a scientific application model of interactive marketing of mobile electronic commerce.
\end{abstract}

\section{Introduction}

With the awakening of people's consciousness on living conditions, it's imperative to implement technological and revolution because of people's self-requirements in reality. Therefore, guided by knowledge and teleological improvement, human beings create internet that has a revolutionary impact, meeting with the demands of people are seeking to improve the method of information interaction instead of structure based on vital severe, so that to build a digital space over geographical and reality. With the help of the instant massage, People's interpersonal communication can be smoother in such a space somehow. Combined with actual demands of society, internet was expanded in more mobile terminal and widely used in kinds of areas in modern society, such as economic, social security, education, etc. While the evolution and changes of internet technology benefit the economic development best without the limits of areas, through which a free cross-regional E-commerce model was created. It was focused not only on Ecommerce itself but also brilliant marketing programs based on interactive cooperation marketing.

This paper outlines the contents involved in M-commerce interactive marketing, describing the marketing characteristics, analyzing the marketing categories, constructing technology support plan, in order to help people establish a scientific M-commerce interactive marketing system and a channel expansion for modern enterprises. Increase enterprises influence, making a solid foundation of enterprises' brand building.

\section{The Contents Involved in M-commerce Interactive Marketing}

It should be clear what is M-commerce interactive marketing first before learning about more Ecommerce interactive model. Based on internet technology support, M-commerce makes a zerodistance communication between client and E-business manager to guarantee the timeliness, interactivity, directness and individuality of a marketing campaign through mobile communication equipment and terminal. With the help of more effective and targeted strategies, marketing enterprises can make a scientific marketing program according to group demands and reduce marketing costs or increasing revenues, which benefits both E-commerce enterprise and client. In a whole, marketing has been dramatically improved. clients' satisfaction increased as well thanks to E-commerce interactive marketing.

People should have ability to collect customers' preference and internal demand, then formulate a marketing plan and offer marketing approaches. Building more attractive mobile terminals for groups, making a diversion group according to customers’ preference and taking targeted strategies to each group are involved in M-commerce interactive marketing. 


\section{The Specific Features of M-commerce Interactive Marketing}

Enterprises expect to fulfill its values of M-commerce on condition that grasping the specific characteristics of interactive marketing, building a scientific interactive marketing system based on its characteristics.

There are following characteristics contained in M-commerce interactive marketing:

Firstly, the mobile environment will increase trust of customers. As known to all, mobile network based on internet technology make it possible that internet users' zero-distance communication. There creating a trusting relationship between business managers and customers for intimately service and clear guidance in E-business. Customers can see others' trust or free evaluation of online shopping information, increasing the marketing confidence. Internet technology leads to a exclusive marketing community by intimate service even better than real environment and improve a marketing influence and credibility.

Secondly, the timely mobile environment ensures consumers' freedom. Consumers have a free participation and clearly browse clear information on web activities in M-commerce marketing. Meanwhile, it's also a fair and free trade platform that online marketer can contact consumers even they cannot pay timely but have purchase intention. Marketers can cancel appointment booking and redistribution according to the consumers' description so as to sharply ensure their legitimate rights.

Thirdly, the interactive characteristics of mobile environments ensure consumers' satisfaction. Business managers make an investigation on consumers' demands according to the key word and circle of concern by mobile environment. Therefore, marketing enterprises prepare very scientific marketing strategies to attract consumers' attention and a good evaluation.

\section{The Varieties of M-commerce Interactive Marketing}

Except for the characteristics of M-commerce interactive marketing, there outlying some specific categories in M-commerce:

\subsection{Two-dimensional code (Qr code)}

Qr code technology is a new marketing model based on mobile Internet, which was made by 2D geometry cooperating with black and white square matrix. Enterprise can create a particular stereogram with high recognition and strong error correcting ability. Combined with infinite change in the lattice, Qr code replace any other publicity means with simple graphs, and its marketing web activities are easily carried to the internet explore with the help of digital camera scanning function of mobile phone. It is possible for consumers to be involved to marketing campaigns and online experience joy.

\subsection{Short Message Address (SMA)}

Besides, another internet technology that helps consumers log into and the server or marketing interface is short message address, which is also one of interactive marketing models. SMA takes advantage of mobile correspondence sending the website in the forms of message, which differs from that of Qr code. Consumers can be easily guided to the marketing campaign web and participated into the even. With the popularity of 3G (The 3rd Generation Telecommunication) and 4G (The 4th Generation Telecommunication), SMA marketing is becoming widely popular. SMA website makes it possible to expand marketing channels by combining WAP push and JAVA plugin according to phone numbers provided by customers.

\subsection{Mobile commercial circle}

Mobile commercial circle is a virtual business circle based on the real business district that provides users with more convenient and punctual service. Consumers can choose best marketing programs and contents of products according to their demands by such circle. The construction of mobile commercial circle makes more reliable business circle that meet individual requirements, consumer's experience and time saving. 


\subsection{Mobile search}

Originally, the internet architecture needs to have the function of information sharing and exchange, information analysis and selection ability. Enterprises can capture the consumers' characteristics and demands by M-commerce searches, collecting and matching the information of goods. A scientific system recommended by scientific analysis on all the collecting information will enhance the effect of E-commerce and guarantee consumers' to purchase goods that match with their minds. Marketing search with individualized recommendation and service that was supported by SMS, WAP, etc., is another scientific types of interactive marketing for both consumers.

\section{The Technical Proposal of M-commerce Interactive Marketing}

Being familiar with the specific characteristics and types of the application attaches great importance to learn about the contents involved in M-commerce interactive marketing. It quite essential to seek out necessary technical support to guarantee a M-commerce interactive marketing scientifically applied in internet.

Therefore, some hypothesis on proposal of in M-commerce is outlined in this paper:

Firstly, to strengthen the consciousness of interactive marketing model, for its good acceptance and evaluation of the new model from consumers on the development with steady steps. However, not all the enterprises have focused on interactive marketing and realize the vital values made by $\mathrm{M}$ commerce, for which missing the boat when making a good marketing program, or being less competitive in M-commerce. So the base of interactive marketing should be focused much on the consciousness of choosing a proper and useful model. Specifically, enterprises managers should pay more attention to social development dynamics and take an active part in business acquisition activities organized by government, absorbing the advanced thought experience and strengthening the understanding of mobile e-commerce marketing model.

Secondly, to cultivate more talented person in electronic marketing. Enterprise management promotion of mobile e-commerce based on the awareness of interactive marketing technology is in need of lots of talents and professionals to implement the electronic commerce in a company. Specifically, personnel department should also pay more attention to selecting employees and suitable position assigning in electronic marketing technology professionals. There's in a need of people that are full of good electronic marketing thoughts and good at setting up electronic marketing professional field. In general, building a mobile e-commerce interactive marketing system needs good interactive e-commerce marketing talent. It's of great significant to choose an appropriate post for mobile e-commerce marketing of enterprise development.

\section{Conclusion}

Above all, enterprise manager should emphasize awareness on building a scientific model and cultivating numbers of talented people after being acquainted with the contents, application characteristics and categories of E-commerce. In other words, the development direction of Mcommerce trend to the construction and a good sense of marketing based on real marketing. It's a inevitable choice of intellectual people to carry out the M-commercial marketing and enhance market competitive power, increase market influence, so that enterprises steadily developed.

\section{References}

[1] Haiyan Wu, A Study on Perceived Values from Customer Participation and Experience within Mobile Electronic Commerce, Modern Economic Information, 15: 124-125, 2016.

[2] Nuo Yu, A Study on Mobile Electronic Commerce Business Model Strategies-A case of household appliance industry, The Centre for Economics and Business Research 13 : 157-159, 2016.

[3] Li Lu, A Study on Values of Customers’ Participation and Experience on O2O E-commerce--A 
case study on dining group purchase, Electronic commerce, 04:161-162,2015.

[4] Linmin Yuan, New Marketing Ideas on Mobile Electronic Commerce Model-- "we media" Marketing, Electronic commerce,04: 111-113, 2015.

[5] Lvwei Chen, Mobile Electronic Marketing Strategies Under New Media Environment, A case study on mobile social application, China Journal of Commercial, 31: 210-211, 2016. 